() (1) https://creativecommons.org/licenses/by/4.0/

ARTIGO

\title{
DE VIGILANTE A GESTOR: O PEDAGOGO EM CONSTRUÇÃO
}

\author{
DANIEL VECCHIO ALVES ${ }^{1}$ \\ ORCID: https://orcid.org/0000-0003-1696-8369 \\ JOÃO PIEDADE ${ }^{2}$ \\ ORCID: http://orcid.org/0000-0002-4118-397X
}

\begin{abstract}
RESUMO: Buscar os contornos da figura do pedagogo exigiu ao presente artigo recuperar marcos de sua própria origem, percebê-los em seu processo histórico-educacional e situá-los no seu campo de atuação. Para isso, ao longo do histórico educacional traçado nesta investigação, notaremos que a necessidade de setorização da ação pedagógica sempre foi explícita nas escolas, pois desde os primeiros sistemas educacionais implantados no Brasil se pensou nas responsabilidades que vão da organização dos espaços de aprendizagem até tarefas mais administrativas. É com base no exercício efetivo das três habilitações pedagógicas principais (coordenação, supervisão e orientação) que pensamos aqui ser possível construir o processo histórico desse cargo escolar, bem como almejar uma gestão pedagógica mais organizada, equilibrada e eficiente em todas as frentes e tarefas que desafiam os pedagogos cotidianamente. Por fim, devemos reconhecer a importância da setorização das atividades pedagógicas no sentido empregado por Rangel (2007), que visa uma especialização colaborativa e não sectária das diferentes habilitações pedagógicas consideradas acima.
\end{abstract}

Palavras-chave: panóptico; gestão educacional; habilitações pedagógicas.

\section{FROM WATCHER TO MANAGER: THE PEDAGOGUE UNDER CONSTRUCTION}

\begin{abstract}
Searching the figure of the pedagogue required the present article to recover landmarks from his own origin, to perceive them in their historical-educational process and to situate them in their field of activity. For this, we will see, throughout the educational history traced in this research, that the need for sectorization of pedagogical action has always been explicit in schools, since the first educational systems implanted in Brazil it was thought about the responsibilities that go from the organization of learning spaces to more administrative tasks. It is based on the effective exercise of the three main pedagogical qualifications (coordination, supervision and guidance) that we think it is possible to build the historical process of the position, as well as, a more organized, balanced and efficient pedagogical management on all fronts and tasks that challenge the pedagogues in the daily school life. Finally, we must recognize the importance of the sectorization of pedagogical activities in the sense used by Rangel (2007), who aims at a collaborative and non-sectarian specialization of these different pedagogical qualifications.
\end{abstract}

Keywords: panoptic; educational management; pedagogical qualifications.

\footnotetext{
1 Doutor em História pela Universidade Estadual de Campinas. São José dos Campos, SP, Brasil. <danielvecchioalves@hotmail.com>

${ }^{2}$ Doutor em Educação pela Universidade de Lisboa. Professor Auxiliar Convidado do Instituto de Educação, Universidade de Lisboa. Lisboa, Portugal. <jmpiedade@ie.ulisboa.pt> 


\section{DE OBSERVADOR A GERENTE: EL PEDAGOGO EN CONSTRUCCIÓN}

RESÚMEN: Buscar los contornos de la figura del pedagogo exigió al presente artículo recuperar marcos de su propio origen, percibirlos en su proceso histórico-educativo y situarlos en su campo de actuación. Luego, veremos, a lo largo del histórico educativo trazado en esta investigación, que la necesidad de sectorización de la acción pedagógica siempre fue explícita en las escuelas, pues desde los primeros sistemas educativos implantados en Brasil se pensó en las responsabilidades que van desde la organización de los espacios de aprendizaje hasta tareas más administrativas. Es con base en el ejercicio efectivo de las tres funciones pedagógicas principales (coordinación, supervisión y orientación) que pensamos aquí ser posible construir el proceso histórico de esto profesional, así como organizar una gestión pedagógica organizada, equilibrada y eficiente en todos las tareas que desafían a los pedagogos en el cotidiano escolar. Por último, debemos reconocer la importancia de la sectorización de las actividades pedagógicas en el sentido empleado por Rangel (2007), que busca una especialización colaborativa y no sectaria de esas diferentes cualificaciones pedagógicas.

Palabras clave: panóptico; gestión educacional; las cualificaciones pedagógicas. 


\section{IMANÊNCIAS DA SUPERVISÃO NA HISTÓRIA DA EDUCAÇÃO}

Buscar um sentido para a figura do pedagogo exigiu recuperar marcos em sua própria origem, percebê-lo em seu processo histórico-educacional e situá-lo no seu campo de atuação. Nessa busca inicial, nos voltamos brevemente à Grécia antiga, quando surgiram os primeiros sistemas educacionais, como o platônico e o aristotélico, que começaram a selecionar e preparar pessoas para desempenhar papéis educacionais e intelectuais na sociedade.

No sistema platônico de ensino, por exemplo, desenvolvia-se a maiêutica socrática, que era uma das mais importantes marcas filosóficas desse sistema, marca essa fundamentada pelas habilidades ou competências que eram estimuladas no aprendiz por um determinado mestre. Admite-se, aliás, que Sócrates foi um dos primeiros pensadores a atingir uma super visão sobre o conhecimento e o processo educacional em si, sensibilizando-se para o processo interior que havia na construção de qualquer aprendizado. Nesse sentido, o conhecimento estaria atrelado às construções ativas de cada indivíduo e não em ensinamentos transmitidos por meio de musas, oráculos ou poetas. Para seu discípulo Platão, a ciência verdadeira, elaborada com base na filosofia, não era transmitida por deuses e nem se aprendia nos cantos, ou seja, "não era imposta de fora à alma. É nela mesma, e por ela mesma, pelo seu próprio trabalho interior, que a alma atinge a ciência, a descobre e a inventa" (Koyré, 1988, p. 15).

Era com base nessa premissa que se constituía a célebre maiêutica socrática tão celebrada por Platão em seus famosos Diálogos, especificamente por meio do personagem de seu mestre Sócrates, cujo ensinamento hoje nos orienta não só à docência, mas também a sua gestão, ou seja, às possibilidades ou às formas de organizar e conduzir a construção do conhecimento. Contudo, nas épocas antiga e medieval, embora tenha surgido uma educação diferenciada caracterizada pelas escolas e pelas primeiras academias, ainda não se põe sistematicamente o problema da gestão do aprendizado promovida por ações coordenadoras, supervisoras e orientadoras: "Isto porque a escola, via de regra, constituía uma estrutura simples, limitada à relação de um mestre com seus discípulos" (Saviani, 2007, p. 16).

Quando essa estruturação começa a ocorrer no período moderno, veremos que a presença da ação coordenadora e supervisora vai assumindo claramente não uma forma maiêutica de agir, de modo a auxiliar construtivamente os agentes educacionais, mas, sobretudo, uma forma de controle e fiscalização de professores e estudantes, chegando ao ponto da coerção punitiva com castigos físicos brutais.

\section{OS FUNDAMENTOS PANÓTICOS DA EDUCAÇÃO MODERNA}

Ao adentrarmos na senda moderna dos processos educativos, o que temos é o surgimento do interesse por uma supervisão como expressão do "desejo de controle máximo dos movimentos e das características dos outros" (Foucault, 1987, p. 177). Ao longo de séculos, almejou-se um sistema educacional cada vez mais controlador, que consistisse em vigiar todos os mestres e aprendizes, levando-os a adotar o comportamento desejado pelos diretores e regentes das instituições de ensino. É assim que chegamos a ideia de panóptico explorada por Michel Foucault em seu clássico Vigiar e punir (1987), em que se traça as consequências do plano do filósofo e jurista inglês Jeremy Bentham, 
que em 1785 planejou uma penitenciária ideal que permitia a um único vigilante observar todos os prisioneiros, sem que estes pudessem saber se estavam ou não sendo observados:

O Panóptico de Bentham é a figura arquitetural dessa composição. O princípio é conhecido: na periferia uma construção em anel; no centro, uma torre; esta é vazada de largas janelas que se abrem sobre a face interna do anel; a construção periférica é dividida em celas, cada uma atravessando toda a espessura da construção; elas têm duas janelas, uma para o interior, correspondendo às janelas da torre; outra, que dá para o exterior, permite que a luz atravesse a cela de lado a lado. Basta então colocar um vigia na torre central, e em cada cela trancar um louco, um doente, um condenado, um operário ou um escolar (Foucault, 1987, p. 223).

Estamos diante de uma linha bastante tênue entre prisão e escola, em que a doutrinação e o controle são os fins de tal estrutura. Mesmo anteriormente a Bentham, encontramos os primórdios dessa base com as origens do Ratio Studiorum das Constituições da Companhia de Jesus, elaboradas por seu fundador Inácio de Loyola e em vigor a partir de 1552. A quarta parte dessas constituições já trazia as linhas mestras da organização didática e, sobretudo, sublinhava o espírito que deveria animar toda a atividade de monitoramento da ordem religiosa. O Ratio dos jesuítas evidenciava a figura do prefeito geral de estudos como assistente do reitor para auxiliar na "boa ordenação dos estudos", a quem "os professores e todos os alunos deveriam obedecer" (Ratio Studiorum, 1635, p. 17).

Nesse documento registra-se a criação da função supervisora "destacada (abstraída) das demais funções educativas e representada como uma tarefa específica para a qual, em consequência, é destinado um agente, também específico, distinto do reitor e dos professores, denominado prefeito dos estudos" (Saviani, 2007, p. 21). O exercício do prefeito dos estudos, ademais, era regulado por trinta regras. A regra $\mathrm{n}^{\circ} 1$, por exemplo, estabelece que é dever do prefeito "organizar os estudos, orientar e dirigir as aulas, de tal arte que os que as frequentam, façam o maior progresso na virtude, nas boas letras e na ciência, para a maior glória de Deus” (Ratio Studiorum, 1635, p. 17).

A regra no 17 , por sua vez, referente à função de "ouvir e observar os professores", estipula que o prefeito deve "[...] de quando em quando, ao menos uma vez por mês, assistir às aulas dos professores; e ler também, por vezes, os apontamentos dos alunos" (Ratio Studiorum, 1635, p. 20). Explicita-se, com essas e outras regras do Ratio Studiorum, as ideias primevas de supervisão pedagógica em língua portuguesa, em frágil dependência a um sistema panótico de relação sócio-intelectual, que se mantém mesmo com o desmantelamento da ordem jesuítica a partir do século XVIII em Portugal:

Com o alvará de 28 de junho de 1759, que institui as reformas pombalinas da instrução pública em decorrência da expulsão dos jesuítas e extinção de seu sistema de ensino, foram criadas as aulas régias. Nessas circunstâncias, ficou um tanto diluído o caráter orgânico da função supervisora concentrada na figura do prefeito dos estudos, que caracterizava a organização do ensino jesuítico. O alvará previa, no entanto, o cargo de diretor geral dos estudos e a designação de comissário para fazer, em cada local, o levantamento do estado das escolas. A julgar pelas cartas dos professores régios de Pernambuco, o comissário exercia, também, a função de diretor de estudos (Saviani, 2007, p. 21-22).

Nesse contexto, a noção de supervisão se concentrava na figura do diretor geral, e os aspectos de direção e coordenação do ensino, em nível local, a cargo dos comissários do diretor geral de estudos. É, sobretudo, no bojo do processo de industrialização que essa organização fiscalizadora dos processos educativos será aperfeiçoada, sendo inevitável nos remetermos a Foucault (1987), na 
averiguação da ideia de panótico como expressão do desejo moderno de controle total dos outros em nível institucional e nacional.

Ocorreu no período industrial europeu e norteamericano uma intensificação do pensamento mercantil na educação, reflexo das mudanças significativas que ocorriam na organização do trabalho, da escola e da família através, principalmente, de ideias relacionadas à organização racional das tarefas (taylorismo, fordismo), bem como ao controle do comportamento (behaviorismo). O foco recai na racionalização do humano, transformando-o em fator econômico, segundo a teoria do capital humano, e colocando para a escola a responsabilidade pela formação de uma mão de obra qualificada para, posteriormente, ser absorvida pelo crescente mercado de trabalho advindo dos primeiros setores industriais do século XVIII.

\section{O PANÓTICO EDUCACIONAL NO BRASIL}

Muitos dos problemas que se colocam atualmente nos exercícios dos pedagogos têm sua explicação na origem da configuração formal da função, geralmente associada ao controle (panótico). Embora tenhamos, no Brasil, como visto, rastros da função supervisora desde o século XVI, sob a influência da Ratio Studiorum dos jesuítas, o modelo de supervisão que terá maior incidência sobre o nosso é o dos Estados Unidos, que deu origem à "Inspeção Escolar" durante o seu processo de industrialização no século XVIII.

No Brasil, os debates que se travaram no final do período monárquico, desde o parecerprojeto de Rui Barbosa de 1882, convergem para um ponto comum: a necessidade de articulação de todos os serviços de educação numa coordenação nacional, o que colocava em pauta a questão da organização de um sistema nacional de educação. Tal questão, aliás, ocupou a atenção de muitos países até o final do século XIX: a estruturação e implantação dos respectivos sistemas nacionais de ensino. Nessa circunstância, veremos que a ideia de coordenação e supervisão vão ganhando contornos cada vez mais nítidos:

[...], em 26 de agosto de 1897, na Lei no 520 extingue-se o Conselho Superior de Instrução Pública dos Estados em prol das inspetorias distritais, ficando a direção e a inspeção do ensino sob a responsabilidade de um inspetor geral, em todo o Estado, auxiliado por dez inspetores escolares. Assim, volta-se à prática, anterior à reforma, de em cada município a fiscalização das escolas estaduais ser exercida por delegados ou representantes das municipalidades. Essa involução na reforma da instrução pública coincide com a consolidação do domínio da oligarquia cafeeira que passa a gerir o regime republicano por meio da política dos governadores. [Contudo,] Seria preciso esperar o período final da República Velha com a crise dos anos 20 para se retomar as reformas estaduais da instrução pública e recolocar o problema da educação como uma questão nacional (Saviani, 2007, p. 25).

O que dá relevância à década de 1920, do ponto de vista do tema abordado por Saviani, é o surgimento dos "profissionais da educação", isto é, o aparecimento dos "técnicos" em escolarização, constituindo-se assim uma nova categoria profissional na área. Tal surgimento foi estimulado pela Associação Brasileira de Educação criada também nessa década, mais precisamente em 1924, o que nos revela a preocupação da ação supervisora em âmbito nacional.

Sob o impulso desenvolvimentista do governo getulista durante a década de 1930, que acelerou o processo de industrialização e urbanização de grandes cidades brasileiras, especialmente no 
sudeste, se intensificaram as pressões sociais em torno da questão educacional da mão de obra para acompanhar o crescente desenvolvimento. Portanto, depois de 1930, toda essa mobilização ganha expressão nacional, passando a ser coordenada pelo poder centralizador do governo de Getúlio Vargas.

Nesse período, foram instituídos órgãos próprios de administração do ensino em substituição às inspetorias. Essa separação entre a "parte administrativa" e a "parte técnica" foi condição fulcral para o surgimento da figura do coordenador e do supervisor pedagógicos como distinta da do diretor. Com efeito, nessa nova divisão do trabalho escolar proposta, assinala Nereide Saviani que cabe ao diretor a "parte administrativa", ficando o supervisor com a "parte técnica" (1981, p. 56). É quando o inspetor assume um papel predominantemente de orientação pedagógica e de estímulo à competência técnica, em lugar da fiscalização para detectar falhas estruturais e aplicar punições, passando esse profissional a ser chamado de supervisor.

Para atender a essa exigência de forma efetiva, instituiu-se, no âmbito das reformas Francisco Campos, o Estatuto das Universidades Brasileiras, que previa a implantação de Faculdades de Educação, Ciências e Letras, a exemplo do que ocorreu na Universidade de São Paulo (USP). Tais faculdades foram responsabilizadas por formar os professores das diferentes disciplinas das escolas secundárias, criando-se, em seu interior, o curso de pedagogia, com a principal incumbência de formar professores das disciplinas específicas do Curso Normal, bem como os técnicos de educação.

Concomitante a essa estruturação no ensino superior, outras reformas de Francisco Campos, de 1931, e as reformas Capanema, de 1942 a 1946, dão sequência, em âmbito nacional, ao processo de reestruturação do ensino brasileiro, que irá desembocar na Lei de Diretrizes e Bases da Educação Nacional promulgada em 20 de dezembro de 1961. Nessas reformas, a categoria "técnico de educação" tinha ainda um sentido muito genérico. Na verdade, os cursos de pedagogia formavam pedagogos, e esses eram os técnicos ou especialistas em educação, e assim permaneceu até os anos de 1960.

\section{A gestão pedagógica tecnicista durante a ditadura militar}

Embora a ideia de supervisão tenha se encaminhado em direção à especificação das atribuições do coordenador e do supervisor pedagógicos até, pelo menos, a década de 1930, sinalizando com isso a sua profissionalização, permanecia, ainda, certa indefinição, especialmente em relação às funções de inspeção. Assim, é verdade que já a reforma Francisco Campos, de 1931, se referia às tarefas de acompanhamento pedagógico, no entanto, tais tarefas eram atribuídas a um inspetor escolar e ainda "se reduziam, na prática, aos aspectos administrativos e de mera fiscalização, não se colocando a necessidade de que esse acompanhamento do processo pedagógico fosse feito por um agente fixo no interior da unidade escolar" (Saviani, 2007, p. 29-30).

Isso só vem a ocorrer nos anos de 1970, quando houve uma maior propagação da educação tecnicista, acentuando nas escolas a tentativa de interligar um sistema empresarial à administração escolar. ${ }^{3}$ Nessa época

\footnotetext{
3 “Alguns dos aspectos que podemos colocar em destaque sobre a política educacional e as realizações da Ditadura Militar no Brasil são: a vinculação da educação pública aos interesses e necessidades do mercado, que se efetivou especialmente no intento de implantação universal e compulsória do ensino profissionalizante; o favorecimento à privatização do ensino; a Educação em Revista|Belo Horizonte|v.36|e222666|2020
} 
[...] aconteceu uma política suscetível aos interesses da classe dominante no país, o que também resultou em secundarização do acesso e da formação dos mais necessitados. A educação deveria assegurar o processo de desenvolvimento econômico do país através da consolidação da estrutura do Capital Humano, assim procurou equacionar o sistema educacional à concepção econômica de desenvolvimento (Leme, 2018, p. 1).

Em síntese, durante a ditadura militar, foi imposta uma política educacional que se materializou nas reformas de 1968 e de 1971, cujos efeitos engendraram uma nova categoria de agentes educacionais. Segundo Leme (2018), havia a necessidade de formarem técnicos com tarefas específicas a serem realizadas nas escolas para o acompanhamento do ensino. Diante disso, o caráter tecnicista do papel do pedagogo teve como consequência "o esvaziamento teórico da formação, excluindo o caráter da pedagogia como investigação do fenômeno educativo. Além disso, a estrutura curricular levou a um currículo fragmentado e aligeirado, visto que havia a necessidade da formação rápida de profissionais que pudessem atuar no ensino, era uma formação de curto prazo e em massa" (Leme, 2018, p. 2).

Ademais, o pensamento de militarização, hegemônico ao longo da década de 1960 e 70, reforçou essa concepção de fiscalização e punição que ainda se sustenta enquanto ferramenta supervisora em muitas escolas. Como um dos exemplos dessa situação de reforço da política de punição e controle educacional, vale destacar o Ato Institucional no 5, de 13 de dezembro de 1968, que deu ao Presidente da República plenos poderes para fechar o Congresso, cessar mandatos, suspender direitos políticos e outras determinações que mantivessem a devida ordem no momento. ${ }^{4}$ Tal política não deixa de impactar a educação com o Decreto lei no 477, de 26 de fevereiro de 1969, que em seu artigo $1^{\circ}$ registra a necessidade da presença de agentes controladores, ora oficiais, ora disfarçados:

Comete infração disciplinar o professor, aluno, funcionário ou empregado de estabelecimento de ensino público ou particular que: I - alicie ou incite à deflagração de movimento que tenha por finalidade a paralisação de atividade escolar ou participe nesse movimento; [...]; III pratique atos destinados à organização de movimentos subversivos, passeatas, desfiles ou comícios não autorizados, ou deles participe; IV - conduza ou realize, confeccione, imprima, tenha um depósito, distribua material subversivo de qualquer natureza; [...]; VI - use dependência ou recinto escolar para fins de subversão ou para praticar ato contrário à moral ou à ordem pública (Decreto Lei no 477 de 26/02/1969).

As formas de controle, tanto no ensino primário quanto no superior, contribuíram fortemente para a construção de um modelo de educação nacional. A escola passou a formar profissionais treinados e instrumentados, mediante doses de um saber funcional e fragmentado visando servir cada vez mais ao mercado. Ao mesmo tempo, foi desmotivada qualquer oportunidade de pensar, criticar ou criar. Houve, portanto, nesse momento, uma supervalorização dos cursos que formavam apenas técnicos de monitoramento dos processos educativos.

Nesse cenário, intensificou-se, também, o projeto de reforma das universidades brasileiras, que deveriam deixar de serem elitistas para tornarem-se centros de formação de profissionais

distinção da oferta de ensino, conforme as classes sociais no país. Foi nesta década que os conteúdos a serem aplicados eram escolhidos por sua relevância social e de discussão em grupos, [...]” (Leme, 2018, p. 3).

4 O Ato Institucional número 5 foi o quinto decreto emitido pela ditadura militar brasileira (1964-1985). Tal ato foi considerado o mais duro golpe na democracia e deu poderes, quase absolutos, ao regime militar, retirando direitos políticos dos cidadãos e passando por cima da própria Constituição do país. O AI-5 entrou em vigor em 13 de dezembro de 1968 , durante o governo do presidente Artur da Costa e Silva.

Educação em Revista|Belo Horizonte|v.36|e222666|2020 
necessários ao desenvolvimento industrial. Como visto durante o governo conservador de Vargas, o cargo de supervisor foi criado num contexto de ditadura, função essa que foi ainda mais estruturada após 1968. Posteriormente, a Lei $n^{\circ}$ 5692/71 instituiu a supervisão educacional como serviço específico na escola de $1^{\circ}$ e $2^{\circ}$ graus (embora já existisse anteriormente). Sua função era predominantemente tecnicista e controladora e, de certa forma, correspondia ao projeto de militarização e tecnicização escolar da época.

No contexto da Doutrina de Segurança Nacional adotada em 1967 e no espírito do mencionado AI-5 de 1968, foi realizada uma nova reforma universitária. Em 1969 era regulamentada tal reforma e aprovado o parecer reformulador do curso de pedagogia, que passava a dar ainda mais ênfase na "preparação predominante dos 'generalistas', como eram chamados aqueles que possuíam o título de especialistas da educação, mas que eram pouco preparados para a prática docente” (Vasconcellos, 2002, p. 85-86).

O curso de pedagogia foi, nesse contexto, organizado na forma de habilitações, em que um núcleo comum centrado nas disciplinas de fundamentos da educação, ministradas de forma bastante sumária, deveria garantir o atendimento a funções específicas da ação pedagógica. Foram previstas quatro habilitações centradas nas áreas técnicas, individualizadas por função, a saber: administração, inspeção, supervisão e orientação (Saviani, 2007). Portanto, a introdução das habilitações nos cursos de pedagogia ocorre no âmbito da concepção que Saviani convencionou chamar de "pedagogia tecnicista" (2007, p. 30) que, a partir de 1969, foi assumida oficialmente pelo aparelho de Estado brasileiro, visando a sua implementação nos cursos de pedagogia de todo o país.

No geral, o anseio dessa pedagogia tecnicista era garantir a eficiência e a produtividade do processo educativo e isso seria obtido por meio da racionalização que envolvia o planejamento do processo sob o controle de técnicos supostamente habilitados, passando os professores a plano secundário, isto é, subordinando-os à organização técnica dos meios. No geral, o que se buscou foi aplicar a "taylorização" ao trabalho de gestão pedagógica, tendo em vista a sua objetificação por meio da divisão técnica do trabalho educativo e do parcelamento das tarefas escolares, tal como teorizara Taylor em relação à organização do trabalho industrial. ${ }^{5}$

A nova estrutura do curso de pedagogia decorrente do Parecer no 252/69 abria, assim, a perspectiva de profissionalização da supervisão, bem como da orientação pedagógica. Com esses cargos em exercício, impunha-se às escolas a presença mais direta de um profissional da educação que auxiliasse no processo de escolarização, visto que o inspetor até então convocado, que assumia responsabilidades junto à docência, não conseguia dedicar-se às necessidades pedagógicas como era preciso e acabava por transitar em muitas atribuições do modo superficial.

Destacou-se, então, o supervisor como especialista pedagógico, que visava garantir a efetividade e eficiência dos meios, dos resultados e do trabalho pedagógico dos professores. Todavia,

\footnotetext{
5 “O planejamento da Universidade de Brasília (UnB), por exemplo, foi orientado pelos pressupostos do planejamento racional, modernizado. $\mathrm{O}$ modelo da UnB é atribuído pelo seu próprio criador à equipe de cientistas da Sociedade Brasileira para o Progresso da Ciência - SBPC. [...]. Na estrutura da UnB organizada administrativa e academicamente num conjunto de faculdades e de institutos centrais, a Faculdade de Educação, para a qual se previra a instalação de uma Escola Normal Superior e de sete departamentos, foi instituída com os objetivos de: 1)formar professores para escolas elementares e normais; 2) formar especialistas em administração, currículos e programas, estatística educacional e testes; 3)oferecer disciplinas pedagógicas às licenciaturas; 4)oferecer pós em educação. [...]. Em decorrência, a educação foi elevada ao status de faculdade, dada a sua multifuncionalidade" (Brzezinski, 1996, p. 61).
} 
observaremos que mudam as políticas e os cargos, mas permanece "o sonho de uma supervisão que acompanha, controla, avalia, direciona as atividades da escola, evitando bloqueios na direção do seu sucesso" (Rangel, 2007, p. 70). Longa e conflituosa será a trajetória do supervisor como aquele capaz de pensar e agir com inteligência, colaboratividade, liderança, dominando conhecimentos técnicos e de relações humanas. ${ }^{6}$

O pedagogo supervisor tem no currículo e no processo didático os seus objetos de controle de qualidade. Valoriza-se, portanto, o pedagogo neste sonho da escola ideal plenamente controlada. Eis evidenciado o sonho panótico da escola militarizada. Assim, pode-se falar, também, de um sonho "tecnicista" da supervisão educacional, em que se pretendia manter a atuação dos supervisores em âmbito pedagógico, entretanto, sem sucesso. O pedagógico não emergia naturalmente no exercício rotineiro dessa supervisão que parecia se preocupar mais com a ordem no sistema de ensino do que com a eficiência da aprendizagem oferecida aos estudantes:

Ao observar o trabalho dos supervisores, percebi que são consumidos por um mundo de decretos, pareceres, deliberações, portarias, resoluções e instruções que parecem não ter fim. Ainda constituem função do supervisor atribuição de aulas excedentes, inscrição de professores para o concurso de remoção, processo de abertura e instalação de escolas particulares, homologação de plano escolar, análise de Regimento Escolar, autorização de cursos, equivalência de estudos, enfim, inúmeras tarefas que auxiliam e organizam toda uma estrutura educacional, porém distantes das escolas e dos professores (Fernandez, 2003, p. 29).

Esperou-se um pedagogo mais presente nas escolas, cuja figura pudesse ser percebida e reconhecida pelos docentes para concretizar um projeto político-pedagógico a estruturar o trabalho como parceiro e conhecedor da escola em que atua, mas, provavelmente por conta dessas e outras responsabilidades, os pedagogos continuavam a desenvolver suas atribuições distantes dos docentes. O trabalho dos supervisores na Diretoria Regional de Ensino era tão necessário quanto o trabalho de acompanhamento e auxílio aos professores dentro da escola. Sendo assim, inúmeras reflexões e ações emergiram no sentido de defender o pedagogo como um profissional que atuasse mais na própria escola em parceria com os professores, cobrindo a falta generalizada de coordenação e de orientação pedagógicas em cada instituição.

A necessidade da presença exclusiva e constante de um profissional que, além do professor, invista no pedagógico não havia sido proposta claramente na estrutura educacional brasileira e há dúvidas se realmente fora esclarecida até hoje. Mas, é de se notar que a forma como foi inserida a supervisão desde o regime getulista acentuou, no interior da escola, a sectarização do trabalho pedagógico, ou seja, a separação total entre os que pensam, planejam, decidem, e os que executam as propostas dadas pelos pedagogos. Desse modo, o professor, que sempre fora o protagonista de suas aulas, a partir do período militar, passa a ser expropriado de seu saber, colocando-se, inadequadamente, entre ele e o seu trabalho a figura do técnico: "A incompetência postulada do professor se apresenta assim como a garantia perversa da continuidade da posição do supervisor, de vez que inviabiliza a

\footnotetext{
6 "De 2 a 6 de agosto de 1976, o MEC (Ministério da Educação) realizou em Brasília o primeiro e único Seminário de Supervisão Pedagógica, que teve como finalidade controlar os sistemas de supervisão educacional que estavam sendo implantados nos Estados. Esse controle, embora não explícito, culminou com um documento sobre a regulamentação da profissão do supervisor e com os Encontros Nacionais, iniciados em 1978 e estes receberam o nome de Supervisores da Educação e não mais escolares ou pedagógicos como anteriormente eram tratados" (Fernandez, 2003, p. 29). 
discussão sobre sua competência presumível e sobre a validade de sua contribuição específica" (Vasconcellos, 2002, p. 86).

\section{A reconsolidação do gerenciamento escolar tecnicista e as indefinições do trabalho do pedagogo}

Diante da falha dos primeiros anos de ação supervisora instituída por políticas centralistas, alguns Estados realizaram medidas e ajustes para aproximar cada vez mais a supervisão da prática docente, como a medida em que se registra pela primeira vez, no Estado de São Paulo, a regulamentação do cargo de coordenador pedagógico no magistério público. Instituída através da Lei Complementar $n^{\circ}$ 114, de 13 de novembro de 1974, a função de professor coordenador encontrava-se como parte da organização básica da escola, conforme explicita o artigo a seguir: "Art. $2^{\circ}$ - São atividades de magistério para efeito deste Estatuto as atribuições do professor e as do especialista de educação que, direta ou indiretamente vinculados à escola, planejam, orientam, dirigem, inspecionam e supervisionam o ensino" (Lei Complementar no 114 de 13/11/1974).

Nos anos de 1980, em prol da valorização do coordenador, a supervisão e o exercício de sua especialidade são retirados das escolas, a exemplo, também, do Estado do Rio de Janeiro, que "promove a exclusão dos supervisores dos Centros Integrados de Educação Pública (CIEPs)" (Rangel, 2007, p. 72). Tendo em vista essa valorização dos professores coordenadores, principalmente em São Paulo, há, nesse momento, uma divergência de leis de descentralização e autonomia na política educacional nacional, especialmente no período de 1983 a 1999, trazendo às unidades escolares maior autonomia nas decisões pedagógicas, o que fortaleceu o "objetivo de descentralização do sistema de ensino e da autonomia da escola" (Rigueto, 2016, p. 65). ${ }^{7}$

Mesmo com essa crescente autonomização na prática docente e na gestão pedagógica das escolas, os anos de 1990 vieram a caracterizar as escolas públicas como catalisadores do modelo gerencial de empresas. Volta-se, nessa década, a desenhar um técnico da educação unilateral e controlador. Na motivação de uma liderança escolar ideal, energiza-se a força transformadora que começou por ressignificar a antiga supervisão na prática do coordenador pedagógico, no sentido de revalorizar a sua formação e ação, reconhecendo alguns de seus aspectos gerais e específicos. Tendo em vista esse modelo, a Lei de Diretrizes e Bases da Educação Nacional de 1996 foi a primeira que enfatizou e sistematizou de fato as atividades do pedagogo especialista. Nela, são registradas as funções do supervisor, do orientador e do coordenador pedagógico como meros desdobramentos das tarefas da antiga inspeção escolar. Os artigos a seguir registram claramente tais funções:

Art. 33 - A formação de administradores, planejadores, orientadores, inspetores, supervisores e demais especialistas de educação será feita em curso superior de graduação, com duração plena ou curta, ou de pós-graduação. Art. 34 - A admissão de professores e especialistas no ensino oficial de $1^{\circ}$ e $2^{\circ}$ graus far-se-á por concurso público de provas e títulos, obedecidas para inscrição as exigências de formação constantes desta lei. Art. 35 - Não haverá qualquer distinção, para efeitos didáticos e técnicos, entre os professores e especialistas subordinados ao

\footnotetext{
7 Recentemente, o cargo de coordenador pedagógico teve sua forma de ingresso alterada. Sua designação passa a ser "precedida não mais por concursos, mas pela escolha entre os docentes de cada unidade escolar, pelos seus pares, à época do planejamento escolar, recaindo a preferência dentre os ocupantes de cargo de docente" (Rigueto, 2016, p. 66). 
regime das leis de trabalho e os admitidos no regime do serviço público (Lei nº 9.394 de 20/12/1996).

Apesar de convocar especialistas e especificar tarefas, a mesma LDB causa indefinições ao apresentar incumbências e responsabilidades estabelecidas aos pedagogos e mesmo aos professores, como no artigo 130: "Os docentes incumbir-se-ão de: [...]; III - [...] participar integralmente dos períodos dedicados ao planejamento, à avaliação e ao desenvolvimento profissional; VI - colaborar com as atividades de articulação da escola com as famílias e a comunidade" (Lei no 9.394 de 20/12/1996). Nos artigos supracitados, coloca-se a pedagogos e professores múltiplas responsabilidades que, por vezes, exigem uma múltipla formação, cobrindo tarefas para gerenciar, articular e orientar a aprendizagem.

Não podemos deixar de esclarecer aqui que essa gama de responsabilidades contribui para uma sensação de permanência na indefinição das funções do pedagogo: "A clareza das leis é dificultada pelo acúmulo de tarefas que se atribui ao pedagogo, o que não lhe permite concisão na hora de priorizar as atividades no cotidiano escolar, [...]" (Lima, Santos e Silva, 2012, p. 3). No decorrer dos anos 2000, inicia-se uma abertura para um fortalecimento ainda maior do pensamento empresarial na gestão pedagógica das escolas. No início desse novo milênio, a necessidade de uma mão de obra mais especializada fez com que a perspectiva dos setores empresariais se aproximasse da educação de modo a determinar metas de produção e desempenho por meio de programas avaliativos e outras políticas públicas.

Uma nova ferramenta de controle exercida na ótica empresarial se fortalece na educação. Para isso, há uma intensificação do processo avaliativo como estratégia de controle dos processos pedagógicos desenvolvidos nas escolas. Logo, tais processos continuaram a ser pensados fora do espaço escolar, pois se resumiam a "avaliar os alunos, as escolas, os professores e, a partir dos resultados obtidos, condicionar a distribuição de verbas e a alocação dos recursos conforme os critérios de eficiência e produtividade" (Rigueto, 2016, p. 73).

Nesta senda, o governo acabou intensificando o ideal de eficiência e de produtividade nas escolas, além de propiciar uma abertura para que, no campo educacional, viesse a ocorrer uma grande quantidade de parcerias entre o setor público e o privado. Bancos, indústrias, ONGs e outros grupos se organizam em movimentos da sociedade com o objetivo de melhorar a qualidade da educação. Mas, como dito, tais parcerias tenderam a organizar o trabalho escolar sob a ótica do modelo gerencialista, privatizando cada vez mais o controle do processo pedagógico e precarizando o trabalho docente, ao manter os professores e pedagogos atarefados e mal remunerados, bem como distantes do poder de decidir sobre as formas e os conteúdos a serem utilizados em sala de aula.

São processos de gestão verticalizados que permitem elevar o grau de controle sobre os profissionais da educação, a título de garantir a obtenção de metas e índices nas avaliações externas, definindo objetivos de produtividade. Nesse cenário educativo, voltamos, em partes, aos problemas identificados durante a ditadura militar, quando a organização do trabalho pedagógico da sala de aula e da escola "ficou cada vez mais padronizada, esvaziando a ação dos profissionais da educação sobre as categorias do processo pedagógico [...]" (Rigueto, 2016, p. 74).

Os processos participativos e de tomada de decisões educacionais no cumprimento e na execução de ações continuam sendo pensadas fora das unidades escolares. Essa é uma das 
características do gerencialismo como ferramenta de organização do trabalho escolar. Nessa perspectiva, há uma tendência em padronizar e individualizar as relações entre os agentes educacionais e, dentre as mazelas promovidas por esse modelo, destacamos a responsabilização do indivíduo não só pelos seus afazeres, mas também por monitorar os afazeres de seus pares.

Nesse contexto, ao se desvalorizar os processos, a atenção se volta apenas para a execução dos procedimentos, empobrecendo o nível pedagógico das instituições escolares. O governo federal segue desenvolvendo mecanismos que visam motivar a sociedade a vir a ser, também, responsável pela qualidade de ensino. Contudo, quem define os parâmetros dessa qualidade é somente o governo. Lembremos que, nos últimos 40 anos, textos legais, nos âmbitos federais, estaduais e municipais têm oferecido diretrizes para a atuação do pedagogo, representando, porém, atribuições e expectativas limítrofes quanto ao seu desempenho e suas possibilidades de atuação no ambiente escolar, problemas que ainda estão longe de serem resolvidos.

\section{O PARADIGMA DO PROFESSOR COORDENADOR NAS ESCOLAS ESTADUAIS PAULISTAS}

O setor educacional do governo do Estado de São Paulo, que é o principal exemplo a ser explorado aqui, executou a extinção do cargo de coordenador pedagógico do quadro do magistério através da Lei $n^{\circ} 9.289$ de 26 de dezembro de 1995. O motivo que ocasionou tal extinção está relacionado ao processo de conceder mais autonomia e poder de decisão para o corpo docente de cada escola, que deve elaborar seu próprio projeto pedagógico de acordo com suas respectivas realidades e necessidades. As ações pedagógicas passam, portanto, a se concentrar na figura do professor eleito "professor coordenador".

Com um profissional mais próximo aos docentes e desenvolvendo um relacionamento mais efetivo com a escola, a Secretaria Estadual de Educação do Estado de São Paulo (SEE/SP) entendeu, desde a segunda metade da década de 1990, que o professor coordenador é um elemento chave no planejamento e no desenvolvimento do trabalho pedagógico. Porém, a dificuldade de implementação desse cargo é visível nas escolas estaduais até hoje. $\mathrm{Na}$ esteira dessas dificuldades, em 7 de abril de 2000 é publicada a Resolução SE n ${ }^{\circ} 35$, dando novos contornos ao trabalho do professor coordenador. Com essa resolução, a SEE/SP considera importante que o professor coordenador venha a:

\footnotetext{
III - assessorar a direção da escola na relação escola/comunidade; IV - subsidiar os professores no desenvolvimento de suas atividades docentes; $\mathrm{V}$ - potencializar e garantir o trabalho coletivo na escola, organizando e participando de oficinas; VI - executar, acompanhar e avaliar as ações previstas no projeto pedagógico da escola (Resolução SE no 35 de 07/04/2000).
}

De início podemos observar nessa Resolução $\mathrm{n}^{\circ} 35$ que novas dimensões foram incorporadas ao trabalho do professor coordenador. Dentre essas dimensões encontra-se o movimento de articulação do trabalho do professor coordenador com o do diretor de escola e com a Diretoria de Ensino da SEE/SP, além das tarefas de supervisão e oficina pedagógica, que visam diminuir o distanciamento entre o pedagogo e o trabalho docente. No entanto, percebe-se de imediato certa sobrecarga de funções e tarefas pedagógicas por parte desse profissional. 
Tal cargo foi sendo cada vez mais valorizado no Estado paulista. Corroborando o nosso entendimento sobre a extinção do coordenador pedagógico em função do professor coordenador, já no ano de 1997 foi promulgada uma resolução em que a SEE/SP considerou a "importância da atuação do professor com a função de Coordenação Pedagógica no processo de articulação e mobilização da equipe escolar na construção do Projeto Pedagógico da unidade educacional" (Resolução SE no 76 de 13/06/1997).

Parece-nos que a Secretaria Estadual de Educação de São Paulo, ao não utilizar a denominação professor coordenador (o que virá a fazer posteriormente) nessa resolução de 1997, já intenta legitimar o espaço da coordenação pedagógica como sendo um espaço a ser ocupado por um docente. De fato o professor coordenador situava-se mais próximo dos docentes, na medida em que seu trabalho se relacionava diretamente com o grupo de professores por ele coordenado, assegurando a execução e a formatação de suas ações por meio de reuniões pedagógicas com seus próprios colegas de profissão. Concordamos que o exercício concomitante de coordenação e docência contribuiu para ampliar e estreitar sua relação com os outros docentes e com os problemas enfrentados em cada escola.

Sob esse prisma, no ano de 2007, o governo do Estado de São Paulo apresentou uma nova agenda para a educação pública composta por dez metas a serem cumpridas até o ano de 2010, dez ações para serem implantadas nas escolas e cinco medidas para que essas ações fossem executadas. $\mathrm{Na}$ primeira medida da lista, encontramos a "expansão da função de professor coordenador e a meta de seleção de doze mil professores coordenadores até dezembro de 2007. Entre as metas e as ações que compõem a agenda da reforma educacional mencionada, foi publicada a Resolução SE no 88, de 19 de dezembro de 2007, atribuindo ao professor coordenador ampla responsabilidade pela introdução, execução e pelo monitoramento de metas e ações na escola, situando-o como gestor implementador da política de melhoria da qualidade do ensino, com os seguintes objetivos:

Art. $1^{\circ}$ - ampliar o domínio dos conhecimentos e saberes dos alunos, elevando o nível de desempenho escolar evidenciado pelos instrumentos de avaliação externa e interna; - intervir na prática docente, incentivando os docentes a diversificarem as oportunidades de aprendizagem, visando à superação das dificuldades detectadas junto aos alunos; - promover o aperfeiçoamento e o desenvolvimento profissional dos professores designados, com vistas à eficácia e melhoria de seu trabalho. [...]. Art. $2^{\circ}-\mathrm{O}$ docente indicado para o exercício da função de Professor Coordenador terá como atribuições: I - acompanhar e avaliar o ensino e o processo de aprendizagem, bem como os resultados do desempenho dos alunos; II - atuar no sentido de tornar as ações de coordenação pedagógica um espaço coletivo de construção permanente da prática docente; III - assumir o trabalho de formação continuada, a partir do diagnóstico dos saberes dos professores para garantir situações de estudo e reflexão sobre a prática pedagógica, estimulando os professores a investirem em seu desenvolvimento pessoal; IV - assegurar a participação ativa de todos os professores do segmente/nível objeto da coordenação, garantindo a realização de um trabalho produtivo e integrador; V - organizar e selecionar materiais adequados às diferentes situações de ensino e aprendizagem; VI conhecer os recentes referenciais teóricos relativos aos processos de ensino e aprendizagem, para orientar os professores; VII - divulgar práticas inovadoras, incentivando o uso de recursos tecnológicos disponíveis (Resolução SE no 88 de 19/12/2007).

Com certo acúmulo de objetivos e atribuições que mesclam atividades docentes e gerenciais, como esse professor coordenador designado pelas escolas estaduais paulistas poderia administrar ou planejar o seu tempo para conseguir efetivar tantas tarefas divergentes? O "como" acumular tais ações é que parecia ficar a desejar em meio a tantas resoluções e responsabilidades designadas pela Secretaria Estadual de Educação. Quanto ao credenciamento desse profissional, entre 
os anos de 2007 até abril de 2012, o processo de designação do docente para a função de professor coordenador ocorria em conformidade com o artigo $5^{\circ}$ da mesma Resolução SE $n^{\circ} 88$, que estabelecia:

I - credenciamento obtido em processo seletivo a ser organizado pela Diretoria de ensino, consistindo de uma prova escrita; II - realização de entrevista individual; III - apresentação de projeto que vise à melhoria do processo de ensino e aprendizagem de uma unidade escolar; IV - ato de designação para a função de Professor Coordenador, editado pelo Diretor de Escola, [...] (São Paulo, Resolução SE no 88 de 19/12/2007).

Tais etapas apresentavam-se de modo a impedir que preferências pessoais ocorressem na seleção do docente para o cargo de coordenadoria. Porém, a partir de 2012, enquanto o supervisor continuou a ser escolhido pelas escolas estaduais via concurso público, o professor coordenador passou a ser eleito por um conselho de docentes. Além disso, para assumir o posto de trabalho de professor coordenador, o docente nunca precisou e ainda não precisa ser um pedagogo de formação.

A figura do professor coordenador foi idealizada de modo a ampliar o atendimento da coordenação nas escolas paulistas por meio de reuniões coletivas entre os docentes, de modo que favoreçam momentos de reflexão da prática pedagógica voltados para o aperfeiçoamento ou atualização do serviço educacional prestado à comunidade. Por meio de um trabalho articulado entre a unidade escolar e a Diretoria de Ensino, o professor coordenador, com toda sua experiência docente, visa garantir a integridade dos currículos do ensino fundamental e médio. Foi justamente com esse compromisso que sua função foi sendo desenhada pelos administradores da educação.

No entanto, nos primeiros balanços da atuação desse profissional, foi observado que sua função exigia, cada vez mais, um controle de metas e de desempenho via avaliações externas. Logo, parece que não existia e ainda não existe a possibilidade de as escolas optarem por projetos pedagógicos diferenciados, que atendam suas necessidades específicas, diante dos padrões ou resultados a serem atingidos nas avaliações estaduais e federais. A perspectiva de responsabilizar as escolas pelo resultado alcançado por meio da medição de desempenho dos estudantes nas provas, na prática criou uma camisa de força na instituição educadora, visto que se reduzem a ensinar utilizando apenas questões objetivas e simplificando todo processo educacional ao conteúdo específico que é cobrado nos testes.

Desse modo, o controle burocrático e autoritário sobre o trabalho pedagógico permanece, mesmo com o aumento da convocação de professores coordenadores nas escolas estaduais paulistas:

O que a princípio proporcionaria a construção de um projeto político-pedagógico onde as questões específicas da realidade dessa ou daquela escola fossem realmente consideradas, promovendo um processo político e democrático, e de uma possível ruptura com as normatizações postas pela reforma educacional, a autonomia acabou sendo incorporada nas escolas mediante as restrições e privações existentes na grade curricular, nas avaliações, nos currículos, na distribuição das turmas e em outras proposições pensadas em nível central para serem executadas na escola (Rigueto, 2016, p. 71).

Dessa maneira, a importância dada ao IDESP (Índice de Desenvolvimento da Educação do Estado de São Paulo) e ao IDEB (Índice de Desenvolvimento da Educação Básica), índices que quantificam o quanto os alunos aprenderam através do seu desempenho no SARESP (Sistema de Avaliação e Rendimento do Estado de São Paulo) e no SAEB (Sistema de Avaliação da Educação Básica), respectivamente, nos faz compreender a forma na qual a SEE/SP expressa o seu entendimento sobre a qualidade da educação. Sob esse aspecto, o professor coordenador assume a postura de um 
gerente, supervisionando a linha de produção de uma empresa, verificando se a produção está em ritmo e conteúdo adequados. Demonstram conduzir uma prática de vigilância ao "que" e não ao "como" do que está sendo ensinado em sala de aula, registrando sistemática e distanciadamente os conteúdos desenvolvidos pelo docente para posterior verificação de supervisores externos das Secretarias e Diretorias de Ensino.

As visões alternativas de organização do trabalho pedagógico no interior da escola vão ficando cada vez mais restritas ante o peso avassalador das avaliações externas, consultorias e materiais pré-fabricados que engessam a atividade da escola e se associam a processos de mediação internos, ancorados numa gestão verticalizada que fragiliza os objetivos, os conteúdos e os métodos de ensino. Nesse cenário educacional, "Educadores, pais e alunos foram alijados da possibilidade de construir coletivamente alternativas para a educação paulista, explicitando, mais uma vez, o conteúdo autoritário implícito nas inovações implementadas" (Rigueto, 2016, p. 72).

Ademais, a possibilidade de formação de um profissional polivalente na figura do professor coordenador de inúmeras escolas, que teve como eixo condutor o toyotismo, que determina, nos processos de trabalho, a superação de uma especialização desvinculada do caráter de totalidade de um exercício, evidentemente falhou. Como veremos a partir do próximo tópico, isso proporcionou a abertura de um ressurgimento mais construtivo e colaborativo da figura do pedagogo especialista em educação nas escolas de algumas redes municipais de ensino do Estado de São Paulo, agora não mais no papel do coordenador ou do supervisor, mas na liderança do orientador pedagógico.

A conclusão que deriva dessa análise é a necessidade e a possibilidade da formação ampliada e, ao mesmo tempo, específica do pedagogo, comprometido, principalmente, com as necessidades orientacionais que visam diretamente os processos de formação e de aprendizagem das escolas. Veremos que alguns planos municipais de educação tentam valorizar as tarefas de orientação no intuito de superar a distância entre a parte teórica e a prática da docência, com base em eixos educacionais já amplamente discutidos. Portanto, é mais do que necessário ultrapassar as barreiras avaliativas padronizadas e permitir que as escolas tenham gestores que se atentem mais qualitativamente às necessidades gerais e específicas do trabalho pedagógico, propondo possibilidades aos docentes de construir um trabalho mais colaborativo e inovador de ensino.

\section{A ORIENTAÇÃO PEDAGÓGICA FACE ÀS FRAGILIDADES DA SUPERVISÃO E COORDENAÇÃO: AS REFORMAS EDUCACIONAIS DAS SECRETARIAS MUNICIPAIS PAULISTAS}

Vimos que a implementação do cargo de professor coordenador não resolveu o problema da ingerência pedagógica das escolas estaduais paulistas, principalmente pela sobrecarga de tarefas e de metas relativas tanto à coordenação quanto à supervisão, atividades que o distanciava da orientação pedagógica. No entanto, a superação dessa ausência do trabalho orientacional é uma questão que pode ser resolvida com base em outras formas de organização do trabalho escolar do pedagogo, formas que reconheçam e preservem o espaço da formação pedagógica dos professores. Trata-se da tendência que tem surgido em muitos planos municipais de educação das cidades do Estado de São Paulo.

Percebendo a continuação do problema de gestão pedagógica, muitas secretarias municipais começaram a regulamentar, de modo mais específico, os cargos pedagógicos, reconhecendo 
suas habilitações como a coordenação, as funções de supervisão e, também, a orientação pedagógica, sendo esta última aquela com estratégias mais diretamente vinculadas à atividade docente. No município de São Paulo, por exemplo, com a Lei no 14.660 (2007), é que foi regulamentado o trabalho dos profissionais da educação na rede municipal de ensino. A lei estabelece, em seu artigo $6^{\circ}$, que há duas classes de profissionais na rede: a classe de docentes e a classe de gestores educacionais, separando a docência da gestão.

Segundo o artigo $7^{\circ}$ da referida lei, compreende-se por classe de gestores educacionais "O agrupamento de cargos de natureza técnica e denominação diversa". Nessa classe, inclui-se o orientador pedagógico. Claro que essa diferenciação de habilitações tende a gerar uma sectarização da ação do pedagogo na escola, que pode se tornar cada vez mais isolada mediante a vinculação do seu trabalho a cada uma das habilidades requeridas. No entanto, o desafio municipal a ser ressaltado consiste justamente na realização de estratégias orientacionais e formativas construídas pelos pedagogos com os próprios docentes e representantes discentes, para que, assim, a escola se distancie gradualmente da lógica industrial do trabalho ou de um ensino meramente transmissivo.

Cabe destacar aqui a função da orientação para além da prática "conselheira", prática essa que visa limitar as escolhas do educando pelo prisma do orientador, fazendo da gestão pedagógica uma gestão de produtos e não de processos. Daí que a orientação pedagógica tenha como pressuposto básico a liberdade de escolha, pois se não há escolhas a fazer então não há orientação voltada para a aprendizagem (Leme e Silva, 2014). Com isso, faz-se necessário exaltar a importância de como o pedagogo pode e deve atuar nas funções de orientador, suprindo essa carência formativa no seio da gestão escolar.

Apresentaremos aqui, como tentativa da superação dessa carência, alguns exemplos proporcionados pelo Plano Municipal de Educação (2015-2025) do município de São José dos Campos, situado na região do Vale do Paraíba do Estado de São Paulo. Nesse plano, encontra-se uma forte ênfase na reestruturação e no esclarecimento das habilitações do pedagogo, visando, assim, a reorganização do trabalho da equipe de pedagogos das escolas:

(18.3) [O Plano propõe] reestruturar as carreiras dos demais profissionais da educação que não pertencem à categoria do magistério, visando a melhoria das ações de apoio ao trabalho pedagógico e educacional; [...]; (18.5) garantir atenção especial aos professores iniciantes, disponibilização de informações, procedimentos e estratégias que facilitem o pleno exercício de suas funções; [...]; (18.7) instituir programa de acompanhamento dos profissionais do quadro do magistério, por meio de avaliação institucional, que produza subsídios para a organização da formação continuada visando a melhoria do desempenho individual e coletivo; [...] (Plano Municipal de Educação, 2015, p. 23).

$\mathrm{Na}$ intenção de reestruturar as carreiras pedagógicas, as metas subsequentes dão margem ao modo como tal reestruturação deve ocorrer, com a implementação de programas locais de formação continuada, de programas de apoio ao professor ingressante, além do programa de acompanhamento (supervisão) do trabalho dos docentes. A organização das metas em programas escolares possibilita retirar a carga pesada de tarefas e responsabilidades por parte de um único gestor pedagógico, o que ocorria e ocorre com coordenadores e supervisores de muitas escolas atuais. $\mathrm{O}$ foco nos programas educacionais fornece a abertura para múltiplas lideranças e participações, destituindo a ideia de um único profissional da educação polivalente responsável, como o professor coordenador das escolas 
estaduais, horizontalizando, dessa forma, os diversos compromissos com os espaços de formação e supervisão, visto que os programas podem e devem ser mediados em grupo.

Trata-se aqui de transformar a ideia de habilitações imposta pelo tecnicismo militar durante as décadas de 1960 e 70, de modo a não isolá-las em suas práticas singulares. Estamos lidando aqui com dois extremos problemáticos: a necessidade de divisão do trabalho do pedagogo nas escolas e o consequente isolamento de suas funções. A meta 19.4, por exemplo, do citado Plano Municipal de Educação de São José dos Campos, visa "estabelecer legislação específica para regulamentar a gestão democrática" (Plano Municipal de Educação, 2015, p. 24). Parte desse interesse "democrático" consiste em manter e aprimorar a colaboração entre as habilitações pedagógicas, sem deixar de pressupor a imersão e o estudo dos cargos pedagógicos para ampliar e melhorar o exercício dos programas de apoio estipulados: (19.5) “ampliar os programas de apoio, incentivo e formação [...], garantindo o desempenho pleno de suas funções" (ibidem).

A regulamentação de cargos e a ampliação dos programas pressupõem não só a integração de funções e práticas, como também a especialização das tarefas, expondo a necessidade do aumento do quadro de pedagogos das escolas municipais, desejando, com isso, atingir melhorias no processo de aprendizagem escolar. Por entre essas e outras metas é que chegamos à conclusão de que algumas Secretarias Municipais de Educação têm se mostrado mais aptas a repensar e reorganizar o trabalho do pedagogo nas escolas, tanto que, hoje, dependendo do município, podemos encontrar em exercício nas escolas até quatro pedagogos, envolvendo coordenador, psicopedagogo, orientador pedagógico e orientador educacional.

Porém, a realidade de muitas escolas municipais, como as de São José dos Campos, ainda é outra, pois, ao escalar orientadores para compor a equipe de gestão pedagógica, as coordenadorias e as supervisões foram abandonadas enquanto cargos internos das escolas, fazendo-nos voltar ao velho problema do acúmulo de tarefas do pedagogo. A estrutura escolar oferecida por essa rede municipal de ensino tem suas funções internas de coordenação e supervisão arcadas pelos próprios orientadores pedagógicos e educacionais.

Numa estrutura diferente, mas vivenciando problemas educacionais similares no ensino fundamental, lembremos que as escolas estaduais paulistas possuem, no geral, até três profissionais voltados exclusivamente para as funções pedagógicas: dois professores-coordenadores e um supervisor, sendo este último cargo apenas designado para as escolas estaduais da capital paulista. Tal preocupação organizacional das funções específicas dos pedagogos até pode ser observada no mencionado Plano Municipal de Educação de São José dos Campos, cujas metas visam ações transformativas, tendo o apoio do recém construído Laboratório de Educação Digital e Interativa (LEDI) instalado no Centro de Formação de Educadores do município, estrutura que passa a servir principalmente a seguinte meta: "(7.11) incentivar o desenvolvimento de tecnologias que aprimorem os procedimentos e processos de gestão das escolas; [...]” (Plano Municipal de Educação, 2015, p. 14).

Mesmo com todas essas metas especificadas, ainda há uma verdadeira indefinição dos cargos e uma desorganização das equipes de trabalho, problemas que precisam ser superados urgentemente. No caso da indefinição das diferentes habilitações do pedagogo, ela contribui, muitas vezes, para o desvio de funções, para a sobrecarga do profissional eleito coordenador, supervisor, orientador ou mesmo do diretor, no caso das escolas em que ainda nenhuma dessas funções são exercidas por profissionais específicos. Esse cenário evidencia a falta de gerenciamento pedagógico na 
maior parte das escolas públicas brasileiras, ocupando ou mesmo anulando o tempo da orientação ou da formação, que, podemos dizer, é o coração da prática pedagógica.

De acordo com Mary Rangel (2007), pensar a ação orientacional, coordenativa e supervisora é pensar, de modo mais equilibrado, na maneira como se organiza uma equipe de pedagogos. $\mathrm{Na}$ contramão desses esclarecimentos, temos certa variedade de termos que extrapolam e confundem as respectivas funções pedagógicas aqui em questão. Desde o final dos anos de 1980, observa-se que persiste não um nome, mas uma nomenclatura, ou seja, um vocabulário, um conjunto de termos com que se mantêm, até hoje, diversos modos de designar as funções do pedagogo. Incluemse, nessa terminologia, as expressões supervisão educacional, supervisão escolar, supervisão pedagógica, orientação pedagógica, orientação técnica, coordenação pedagógica, coordenação escolar e coordenação de área ou disciplina.

Nessa senda de classificações, segundo ainda Mary Rangel (2007), podemos e devemos especificar cada uma delas para um melhor funcionamento da gestão pedagógica dos pedagogos. Se a coordenação "é um designativo em que "co-ordenar" quer dizer, etimologicamente, organizar em comum, prever e prover momentos de integração do trabalho entre as diversas disciplinas e entre as diferentes atividades, a supervisão, cujo prefixo "super" que une-se à “visão", designa o ato de "ver" o geral e define-se pelo pretendido monitoramento das atividades específicas desenvolvidas na escola. Para possibilitar essa visão geral e supervisora, "é preciso "ver sobre" e é este o sentido de "super", superior não em termos de hierarquia, mas em termos de perspectiva, de ângulo de visão, para que o supervisor possa “olhar" o conjunto de elementos e seus elos articuladores" (Rangel, 2007, p. 76).

O orientador pedagógico, por sua vez, é quem deve propiciar a reflexão teórica sobre a prática docente e mediar as trocas de experiências entre os professores, bem como exercer a leitura e o debate de estudos e pesquisas atuais sobre a prática pedagógica como um todo: a orientação funda-se no procedimento de construir métodos e estimular o aproveitamento das estruturas fornecidas pela coordenação e supervisão pedagógicas da escola. Trata-se a orientação, portanto, da atividade pedagógica mais próxima da principal função educacional: a docência e seus processos de aprendizagem.

No quadro seguinte sistematiza-se, com base em Rangel (2007), a definição dos três exercícios principais que fundamentam o trabalho do pedagogo nas escolas:

Tabela 1 - Definição das funções pedagógicas proposto por Rangel (2007)

\begin{tabular}{|l|l|}
\hline Habilitação pedagógica & \multicolumn{1}{|c|}{ Definição } \\
\hline \hline Coordenação Pedagógica & $\begin{array}{l}\text { "A coordenação implica criar e estimular } \\
\text { oportunidade de organização comum e de } \\
\text { integração do trabalho em todas as suas etapas. } \\
\text { "Co-ordenar" é organizar em comum, de modo } \\
\text { a prever e prover momentos de integração do } \\
\text { trabalho entre as diversas disciplinas [...], } \\
\text { solicitando estudo e definição de critérios que } \\
\text { fundamentem soluções" (Rangel, 2007, p. 76- } \\
77) .\end{array}$ \\
\hline \hline & $\begin{array}{l}\text { Acompanha, identifica problemas, avalia, } \\
\text { direciona as atividades da escola, evitando }\end{array}$ \\
\hline
\end{tabular}

Educação em Revista|Belo Horizonte|v.36|e222666|2020 


\begin{tabular}{|c|c|}
\hline Supervisão Pedagógica & $\begin{array}{l}\text { autoritarismos e desvios no processo de } \\
\text { aprendizagem. Nessa concepção, o supervisor } \\
\text { será aquele capaz de pensar e agir com } \\
\text { inteligência e equilíbrio, dotado de ferramentas } \\
\text { de observação e boa articulação de ensino. Esse } \\
\text { especialista tem no currículo e no processo } \\
\text { didático os seus objetos de controle de } \\
\text { qualidade, sendo assim crucial para o processo } \\
\text { de aprendizagem. }\end{array}$ \\
\hline Orientação Pedagógica & $\begin{array}{l}\text { "Propicia a reflexão teórica sobre a prática e as } \\
\text { trocas de experiências, a observação e análise de } \\
\text { problemas e soluções comuns. A orientação } \\
\text { também implica criar e estimular oportunidades } \\
\text { de estudo coletivo para análise da prática em } \\
\text { suas questões, em seus fundamentos teóricos e } \\
\text { práticos, que se "trocam" e se aproximam nos } \\
\text { relatos de experiências. [...]. Trata-se de } \\
\text { aproveitar os elos articuladores das atividades } \\
\text { pedagógicas" (Rangel, 2007, p. 76). }\end{array}$ \\
\hline
\end{tabular}

Concordamos com Rangel (2007) que é com base no exercício efetivo dessas três funções pedagógicas assinaladas (coordenação, supervisão e orientação pedagógicas) que se torna possível construir uma gestão pedagógica organizada, equilibrada e eficiente em todas as frentes e tarefas que desafiam os pedagogos no cotidiano escolar. Para tanto, devemos reconhecer a importância da "setorização" das atividades pedagógicas no sentido empregado por Rangel (2007), que visa uma especialização colaborativa e não sectária dessas diferentes habilitações, fundadas gradativamente desde as reformas escolares promovidas pela ditadura getulista. Nesse sentido, a "especialidade" caracteriza-se pelo que congrega, reúne e articula, distanciando-se das repartições militares e industriais, e aproximando-se das propostas cada vez mais colaborativas e especializadas para a organização do ensino.

Portanto, a "setorização" das funções do pedagogo será aqui defendida com base na proposta de Mary Rangel, que se fundamenta na importância das especialidades do trabalho do pedagogo sem desagregá-las ou isolá-las em seus propósitos: "é nesse sentido que setorizar não é sectarizar, mas compreender que o conjunto se faz pelos elos comuns da pluralidade" (Rangel, 2007, p. 94). Com um trabalho setorizado e colaborativo das múltiplas ações dos pedagogos, haverá maior chance de consolidar um espaço educacional em que nenhuma promoção será tão importante quanto à promoção da aprendizagem do discente.

Com base nessa defesa das especificidades pedagógicas e suas necessidades colaborativas de realização, pensamos ser de grande valia refletir sobre a característica vital que deve possuir um pedagogo para a efetivação de suas funções, independente de sua ênfase ou habilitação: possuir uma natureza de liderança. Tal característica passa a ser fundamental, visto que "uma organização educativopedagógica deve ter liberdade para decidir a forma como os objetivos são atingidos e os meios a utilizar" (Santos, 2018, p. 14-15). Portanto, não basta dar autonomia às escolas e aos seus pedagogos, é preciso saber aproveitar produtivamente essa liberdade.

Em grande parte dos estudos sobre liderança na área educacional, visa-se tal aspecto no exercício dos diretores escolares, no sentido de definir a liderança do diretor de duas formas: a liderança 
“instrucional” e a liderança "transformacional" (Burns, 1978; Piedade, 2017; Santos, 2018). ${ }^{8}$ Nesta investigação, afirmamos que tal questão sobre liderança diretiva também pode e deve ser reposicionada aos estilos e exercícios de outros agentes educacionais, como os pedagogos e os professores. Logo, pensamos aqui que o pedagogo pode e deve assumir um estilo de "liderança transformacional", capaz de promover o envolvimento de seu corpo docente e de sua comunidade escolar na direção de um processo de aprendizagem coletivo, sobretudo a partir de métodos inovadores.

A liderança transformacional do pedagogo na escola, ou a falta dela, reflete diretamente no desempenho dos professores e demais agentes escolares, visto que o líder transformacional é alguém que "é capaz de projetar o coletivo para o futuro, levando-o a realizar uma ação com vista a alcançar um objetivo comum que está para além dos objetivos e interesses particulares de cada indivíduo [...]" (Santos, 2018, p. 35). Por isso, recomenda-se que os pedagogos se envolvam nos programas de desenvolvimento profissional dos seus professores e, ainda, que procurem constituir nas suas escolas equipes de professores com potencial para promover estratégias de aprendizagem e liderar a integração das tecnologias educacionais nas salas de aulas.

\section{NECESSIDADES E DESAFIOS ATUAIS DA AÇÃO PEDAGÓGICA}

Vimos, ao longo do histórico traçado nesta investigação, que a necessidade de setorização da ação pedagógica nas escolas sempre foi explícita, pois desde os primeiros sistemas educacionais implantados no Brasil se pensou nas responsabilidades que vão da organização dos espaços de aprendizagem até tarefas mais específicas, envolvendo monitoramento e planejamento das atividades docentes. Sendo assim, enxergamos que a "setorização colaborativa”, proposta por Mary Rangel (2007), é um modelo positivo para pesarmos nos desafios dos pedagogos atualmente em exercício nas escolas públicas. São desafios que possuem suas raízes históricas, principalmente desde os anos de 1960, quando os modelos "militares" e "tecnicistas" relacionados à organização do trabalho escolar tinham como base o monitoramento do comportamento e do próprio conteúdo escolar. Contudo, a partir da década de 1990, vimos que tais modelos passam a ser caracterizados por certa flexibilização operacional, surgindo assim um neotecnicismo toyotista fundado na figura de profissionais polivalentes.

O que percebemos a partir desse período, todavia, é que, mesmo com a inserção de um profissional polivalente, como no caso dos professores coordenadores das escolas estaduais, a organização do trabalho de gestão pedagógica, nesses locais, ainda seguiu princípios bastante sectarizados. Além disso, novos mecanismos foram introduzidos no processo, novas fórmulas surgiram remodeladas, reestruturadas e readequadas ao modelo econômico e político vigente, o que levou o deslocamento do foco "processual para o dos resultados" dos sistemas de avaliação institucional. Portanto, o trabalho na escola vem sendo reorganizado através da transferência de modelos de gestão utilizados no campo empresarial, ao que se denomina de "pedagogia corporativa" (Rigueto, 2016, p. 91), fazendo dos resultados avaliativos o carro chefe de todo o trabalho de gestão pedagógica.

\footnotetext{
8 "Burns (1978) apresentou dois conceitos de liderança, a liderança transacional e a liderança transformante ou transformacional. Defende o autor que "transformar" aponta para níveis mais profundos de mudança, capazes de gerar alterações radicais na natureza dos contextos, de proporcionar transfigurações na forma e nas estruturas, apontando assim para a liderança transformante ou transformacional. Com base nos trabalhos de Burns, o líder transformacional apresenta um maior grau de comprometimento, uma maior visão estratégica e procura motivar e envolver os outros nos processos de decisão" (Santos, 2018, p. 42-43).
} 
Nessa readequação à lógica empresarial, a avaliação dos resultados passa a ser inscrita como parâmetro do novo modelo de regulação educacional, tendo em vista, unicamente, a qualidade dos resultados. Entendemos que os resultados das avaliações são fundamentais, mas não a ponto de engessar os contornos da organização do trabalho pedagógico nas escolas. No entanto, é explícito que a avaliação vem sendo utilizada mais como uma ferramenta de controle das práticas e dos conteúdos a serem explorados, preocupando-se mais em compor limites aos pedagogos e professores do que comprometida com a qualidade do processo de aprendizagem em si.

Entendemos, ainda, que essas medidas gerenciais, no interior da gestão pedagógica, tendem a diluir os direitos e deveres dos pedagogos e docentes, balizados por resultados imediatos. Satisfatórios ou não, são esses os resultados que passam a orientar e limitar as ações do trabalho do pedagogo de muitas escolas que almejam estampar nas publicidades um largo número de aprovados em índices e concursos de vagas e bolsas educacionais. Tais ações, em realidade, são dificultadas pelo excesso de compromissos de parte a parte, pelos desvios de função de supervisores e orientadores e sua pouca disponibilidade para novos estudos e novas ações, pela falta de parceria e dificuldades de trabalhar coletivamente, fatores que acabam por afetar as tarefas do pedagogo.

É evidente que as funções dos pedagogos não poderiam ser encaradas como controladoras, fiscalizadoras ou punitivas, pois esse tipo de ação não deveria estar presente em nenhum dos profissionais da educação, em relação ao coordenador, supervisor ou orientador pedagógico menos ainda. Por isso, é importante refletirmos sobre uma nova figura do pedagogo estruturada em concepções e perspectivas diferentes. Nessa esteira, o presente artigo se predispôs a analisar o histórico e as principais características da coordenação, da supervisão e da orientação pedagógicas, com suas percepções e seus problemas enfrentados, decorrentes do funcionamento e da organização da escola, bem como da própria formação profissional.

Com tal temática introduzida, tivemos o interesse em aprofundar o histórico do trabalho do pedagogo nos espaços escolares públicos, tomando como base o modelo de ação pedagógica proposta por Mary Rangel (2007). A desorganização e a irrelevância de tais funções, porém, ainda é evidente em muitas instituições públicas, reflexo disso é o fato da educação nacional ainda apresentar altos índices de evasão e baixo aproveitamento. O baixo nível de aprendizagem não deixa de estar relacionado com a desorganização dos setores pedagógicos que, por sua vez, devem funcionar bem para um gerenciamento estável e produtivo dos espaços de aprendizagem e de formação inicial e continuada dos professores, responsabilidades que afetam diretamente a qualidade de ensino.

O descontentamento dos docentes e o baixo nível de aprendizagem da maior parte dos estudantes brasileiros mostram que a equipe escolar precisa ser rearticulada. Nesse contexto, destacamos o coordenador, o supervisor e orientador pedagógicos, no modelo proposto por Rangel, como agentes capazes de expandir seus estilos de gestão e alterar esse cenário negativo, ou seja, são agentes capazes de contribuir específica e colaborativamente para a transformação do espaço escolar. 


\section{REFERÊNCIAS}

Brzezinski, I. (1996). Pedagogia, pedagogos e formação de professores. $5^{a}$ ed. Campinas, SP, Papirus.

Burns, J. M. (1978). Leadership. New York: Harper \& Row.

Fernandez, F. E. (2003). Sobre a coordenação pedagógica: por uma perspectiva docente. São Paulo, Intersubjetiva.

Foucault, M. (1987). Vigiar e punir: nascimento da prisão. Trad. Raquel Ramalhete. Petrópolis, Vozes.

Koyré, A. (1988). Introdução à leitura de Platão. Tradução de Helder Godinho. Lisboa, Editorial Presença.

Leme, E. S. \& Silva, Jacqueline L. da (2014). Supervisão e orientação educacional: entre a teoria e a prática. In: Silva, Jacqueline L. da (org.). Orientação e supervisão educacional: reflexões sobre o fazer pedagógico. Rio de Janeiro, Walk, p. 15-38.

Leme, R. B. (2018). Formação de professores na ditadura militar. In: Anais das Reuniões Regionais da ANPEd, Cáceres-MT, pp. 1-8.

Lima, M. A. P. de \& Santos, D. G. dos \& Silva, T. A. (2012). O coordenador pedagógico e a construção de sua identidade: desafios e realidades. In: Anais do IV EPEPE, Recife, PE, p. 1-12.

Piedade, J. (2017). Os diretores escolares e a integração das tecnologias nas escolas: análise da proficiência, utilização das tecnologias e relação com as práticas dos professores. Tese de Doutoramento em Educação na especialidade de Tecnologias de Informação e Comunicação na Educação da Universidade de Lisboa.

Rangel, M. (2007). A supervisão educacional em perspectiva histórica: da função à profissão pela mediação da idéia. In: Ferreira, Naura S. C. (org.). Supervisão educacional para uma escola de qualidade: da formação à ação. $6^{\text {a }}$ ed. São Paulo, Cortez, p. 69-96.

Ratio Studiorum (1635). Trad. Gustavo Amigó. Antuérpia, Institutio Studiorum Societatis Jesu. Acediddo em 27/12/2018 em http://purl.pt/index/geral/PT/index.html.

Rigueto, R. L. (2016). O trabalho do professor coordenador na escola pública paulista - a formação de uma identidade. Dissertação de mestrado. Campinas, SP, Faculdade de Filosofia e História da Educação da Universidade Estadual de Campinas.

Santos, J. R. L. dos (2018). As TIC na escola pública portuguesa e a sua relação com as lideranças. Doutoramento em Educação Especialidade de Liderança Educacional da Universidade Aberta de Lisboa.

Saviani, D. (2007). A supervisão educacional em perspectiva histórica: da função à profissão pela mediação da idéia. In: FERREIRA, N. S. C. (org.). Supervisão educacional para uma escola de qualidade: da formação à ação. $6^{\mathrm{a}}$ ed. São Paulo, Cortez, p. 13-38. 
Saviani, N. (1981). Função técnica e função política do supervisor em educação. Dissertação de Mestrado. São Paulo, PUC-SP.

Vasconcellos, C. (2002). Coordenação do trabalho pedagógico: do projeto político-pedagógico ao cotidiano da sala de aula. São Paulo, Libertad.

\section{LEGISLAÇÃO}

Decreto Lei no 477 de 26 de Fevereiro de 1969. Brasília, DF. Acedido em 29/12/2018 em http://www2.camara.leg.br/legin/fed/declei/1960-1969/decreto-lei-477-26-fevereiro 1969-367006publicacaooriginal-1-pe.html.

Lei Complementar no 114 de 13 de Novembro de 1974. Institui o Estatuto do Magistério Público de 1. ${ }^{\circ}$ e 2. ${ }^{\circ}$ graus do Estado e dá providências correlatas. Assembléia Legislativa de São Paulo. São Paulo-SP. Acessado em 16/12/2018 no endereço: https://www.al.sp.gov.br/repositorio/legislacao/lei.complementar/1974/lei.complementar-11413.11.1974.html.

Lei $\mathrm{n}^{\circ} 14.660$ de 26 de Dezembro de 2007. Dispõe sobre alterações das Leis $\mathrm{n}^{\circ} 11.229 / 1992, \mathrm{n}^{\circ}$ 11.434/1993 e legislação subsequente. Reorganiza o Quadro dos Profissionais de Educação, com as respectivas carreiras, criado pela Lei $n^{\circ} 11.434 / 1993$, e consolida o Estatuto dos Profissionais da Educação Municipal. Diário Oficial da Cidade de São Paulo. Prefeitura de São Paulo, São Paulo, SP.

Lei no 9.394 de 20 de dezembro de 1996. Estabelece as diretrizes e bases da educação nacional. Diário Oficial da União. Brasília, DF.

Plano Municipal de Educação [2015-2025] (2015). Boletim do Município, no 2280. Secretaria Municipal de Educação, São José dos Campos-SP.

Resolução SE no 88 de 19/12/2007. Dispõe sobre a função gratificada de Professor Coordenador. São Paulo, SP. Acedido em 22/12/2018 em http://siau.edunet.sp.gov.br/ItemLise/arquivos/88 07.HTM.

Resolução SE no 35 de 07/04/2000. Dispõe sobre o processo de seleção, escolha e designação de docente para exercer as funções de Professor Coordenador em escolas da rede estadual de ensino e dá providências correlatas. São Paulo, SP. Acedido em 22/12/2018 em http://siau.edunet.sp.gov.br/ItemLise/arquivos/35 2000.htm.

Resolução SE no 76 de 13/06/1997. Dispõe sobre a continuidade do processo de escolha para designação de professor para o exercício da função de Coordenação Pedagógica, nas escolas da rede estadual de ensino, e dá providências correlatas. São Paulo, SP. Acedido em 18/12/2018 em http://siau.edunet.sp.gov.br/ItemLise/arquivos/notas/76 1997.htm?'Time=8/29/2009\%209:55:08\% 20AM 
Submetido: 13/04/2019

Aprovado: 18/08/2019 